\title{
La idealización de la alteridad: reflexiones sobre sus fundamentos en la historia occidental ${ }^{\star}$
}

\author{
Jean Paul Sarrazin ${ }^{* *}$ \\ Recibido: 2017-05-27 Enviado a pares: 2017-05-30 \\ Aprobado por pares: 2017-06-18 Aceptado: 2017-07-05 \\ DOI: 10.22395/angr.v16n31a10
}

\begin{abstract}
Resumen
Así como fueron considerados "salvajes" o "atrasados", los nativos de las tierras colonizadas por los europeos también han sido objeto de elogios que han llegado hasta la idealización, y que han surgido especialmente entre las élites intelectuales de origen europeo. Este último tipo de discursos e imaginarios, relativamente poco comunes y escasamente estudiados, parece contraponerse al racismo e invitaría a una valoración de la diversidad cultural. Sin embargo, este artículo tiene como objetivo plantear un análisis crítico de dicho elogio de la alteridad, el cual, contrariamente a lo que se suele creer, no es un avance intelectual reciente, sino un discurso basado en antiguos mitos premodernos. Para alcanzar este objetivo, se hizo un análisis hermenéutico de los discursos de autores y colectivos reconocidos en Occidente, quienes han recurrido a términos connotados positivamente para describir las culturas de pueblos no europeos. En esos discursos se observaron algunos patrones generales, lo cual permitió relacionarlos con estructuras míticas de larga duración, tales como el mito cristiano del Jardín del Edén y el mito grecolatino de una Edad de Oro. Como una prolongación de esto, hoy se puede considerar al Otro "natural" y "tradicional" como el ejemplo de un ser humano admirable. No obstante, en este artículo se concluye que ese tipo de representaciones, aunque hoy estimadas como políticamente correctas, se basan en versiones esencializadas de la alteridad, las cuales en realidad reproducen ideales hegemónicos y contribuyen a ocultar la complejidad de la diversidad cultural.
\end{abstract}

Palabras clave: alteridad; representaciones sociales; discursos; modernidad; esencialismo; diversidad cultural; identidad; mitología; hegemonía cultural.

Este artículo es una reflexión que surge principalmente a partir de la investigación realizada por el autor en el marco de su Doctorado en Sociología de la Université de Poitiers, Francia. Dicha investigación contó con el apoyo de una beca del Institut de Recherche pour le Développement (París).

* Antropólogo con Opción en Filosofía, magíster en Migraciones y Relaciones Interétnicas, Doctor en Sociología. Docente-investigador vinculado al Departamento de Sociología de la Universidad de Antioquia. jean.sarrazin@udea. edu.co 


\title{
The idealization of alterity: reflections on its foundations in Western History
}

\begin{abstract}
Just as the natives of lands colonized by Europeans were considered "wild" or "slow," they have also been the object of praise that has gone as far as idealization, and that have emerged especially among the intellectual elites of European origin. This last type of discourses and imaginaries, relatively rare and scarcely studied, seems to be opposed to racism and would invite an appreciation of cultural diversity. However, this article aims to propose a critical analysis of this praise of alterity, which, contrary to what is usually believed, is not a recent intellectual advance, but a discourse based on ancient pre-modern myths. To achieve this goal, a hermeneutic analysis of the discourses of authors and collectives recognized in the West, who have resorted to positively connoted terms to describe the cultures of non-European peoples was made. In these discourses, some general patterns were observed, which allowed them to be related to mythical structures of long duration, such as the Christian myth of the Garden of Eden and the Greek-Latin myth of a Golden Age. As an extension of this, today we can consider the Other "natural" and "traditional" as the example of an admirable human being. However, in this article it is concluded that such representations, although nowadays considered as politically correct, are based on specialized versions of alterity, which in reality reproduce hegemonic ideals and contribute to hide the complexity of the cultural diversity. Keywords: alterity; social representations; discourses; modernity; essentialism; cultural diversity; identity; mythology; cultural hegemony.
\end{abstract}

\section{A idealização da alteridade: reflexões sobre seus fundamentos na história ocidental}

\begin{abstract}
Resumo
Assim como foram considerados "selvagens" ou "atrasados" os nativos das terras colonizadas pelos europeus, também foram objeto de elogios que chegaram até a idealização e que surgiram especialmente entre as elites intelectuais de origem europeia. Este último tipo de discursos e imaginários, relativamente pouco comuns e escassamente estudados, parece contrapor-se ao racismo e convida a uma valorização da diversidade cultural. Contudo, este artigo tem como objetivo propor uma análise crítica do elogio da alteridade, o qual, ao contrário do que se costuma acreditar, não é um avanço intelectual recente, mas sim um discurso baseado em antigos mitos pré-modernos. Para atingir esse objetivo, fez-se uma análise hermenêutica dos discursos de autores e coletivos reconhecidos no Ocidente, os que têm recorrido a termos conotados positivamente para descrever as culturas de povos não europeus. Nesses discursos, foram observados alguns padrões gerais, o que permitiu relacioná-los com estruturas míticas de longa duração, tais como o mito cristão do Jardim do Éden e o mito greco-latino de uma Idade do Ouro. Como uma prolongação disso, hoje pode-se considerar o Outro "natural" e "tradicional" como o exemplo de um ser humano admirável. No entanto, neste artigo, conclui-se que esse tipo de representações, embora hoje estimadas como politicamente corretas, estão baseadas em versões essencializadas da alteridade, as quais, em realidade, produzem ideais hegemônicos e contribuem para ocultar a complexidade da diversidade cultural.

Palavras-chave: alteridade; discursos; diversidade cultural; essencialismo; hegemonia cultural; identidade; mitologia; representações sociais; modernidade.
\end{abstract}




\section{Introducción}

Este artículo tiene como objetivo reflexionar sobre algunas de las representaciones de la alteridad que se han producido en la historia de Occidente. Para alcanzar este objetivo, se analizaron discursos de autores reconocidos o de movimientos sociales donde efectivamente se ha recurrido a términos connotados positivamente para describir la cultura de pueblos no europeos. Así, no se profundizará en las imágenes negativas del Otro, las cuales han sido estudiadas en numerosas investigaciones y desde varias disciplinas como la psicología social, la antropología, la sociología o la filosofía! .

En efecto, se sabe bien que los nativos de las tierras colonizadas por los europeos fueron representados muy frecuentemente como "salvajes" que debían ser civilizados o destruidos, "primitivos" inherentemente inferiores a los europeos, personas sin alma, carentes de dignidad y de derechos, "esclavos naturales" o "adoradores del Diablo" (Bernand y Gruzinski, 1992; Stenou, 1998). Esta situación pasada ha sido denunciada y criticada hasta el cansancio desde la academia contemporánea y desde instituciones nacionales o internacionales (como la Organización de las Naciones Unidas), las cuales han creado múltiples estrategias de comunicación a favor de la diversidad cultural o en contra del racismo y la discriminación (Sarrazin, 2015, p. 168-170).

De manera menos conocida, sin embargo, desde hace siglos también se producen en Occidente discursos donde se elogian aspectos de otras culturas, como sus formas de pensamiento, sus costumbres, su cosmovisión, su espiritualidad. Estos discursos, como veremos, se basan parcialmente en estructuras míticas de larga duración y tienen notables similitudes con los discursos contemporáneos a favor de las culturas no occidentales. Estos tipos de discursos sobre el Otro también merecen un análisis crítico, aunque hoy sean indiscutiblemente considerados como política y moralmente correctos.

Los procesos de representación de la alteridad tienen una profundidad histórica. Se sabe que ciertas leyendas medievales proporcionaron esquemas para que se construyeran imágenes de los pueblos nativos de Asia o de América (Bartra, 1998). Así por ejemplo, la leyenda de los acéfalos (u hombres sin cabeza) permitió que los asiáticos primero, y los americanos después, fueran representados en Europa como acéfalos (Stenou, 1998, p. 22-24). Las representaciones del Otro, por fantásticas que sean, tienen lugar dentro de estructuras de creencias y de valores complejas que permiten a los sujetos comprender no solo la alteridad, sino su propia identidad y el mundo en general (Joffe, 2005).

Las numerosas empresas europeas de conquista dieron lugar a la construcción y difusión siempre creciente de imágenes de los Otros no europeos. El desarrollo de medios de comunicación como la imprenta potenció dicha difusión. Estas representaciones se han basado generalmente en dos grandes modelos para concebir la alteridad (Todorov, 1991): el modelo según el cual, entre más distanciado y diferente sea el Otro, más negati-

A propósito de la denigración de los pueblos colonizados, se ha utilizado, entre otros, el concepto de "ontología colonial" (Maldonado-Torres, 2010). De manera más general, la construcción de estereotipos negativos respecto al Otro es un tema ampliamente documentado, especialmente desde la psicología social (Visonneau, 2002). 
vas son las representaciones a su respecto; este modelo ha inspirado, entre otras cosas, la xenofobia y ciertos nacionalismos. De otro lado, existe el modelo opuesto, según el cual, entre más lejano y diferente sea el Otro, más positivas son las representaciones a su respecto; este es el modelo al que nos referiremos a continuación. A manera de ejemplo de este último, en el canto XIII de La Ilíada, Homero habla de la población más lejana conocida por los griegos, describiendo a sus habitantes como "los más justos entre los hombres". Igualmente, en la Odisea se dice que "en los confines de la tierra [...] la vida para los mortales no es más que dulzura" (citado por Todorov, 1991, p. 305). Para Homero, concluye Todorov, el país más alejado es el mejor; por el contrario, "a nadie se le ocurriría idealizar los vecinos bien conocidos" (p. 306). ${ }^{2}$ ¿A qué se debe esto?

En el primer modelo descrito arriba, una alteridad negativa contribuye a reforzar una identidad positiva, mientras que, en el segundo modelo, se construye una alteridad positiva sobre la base de una identidad negativa o, por lo menos, criticada. Este segundo tipo de imágenes dio lugar a la idea de que ciertos Otros muy lejanos poseerían virtudes que Nosotros desafortunadamente no poseemos. Como veremos, estos discursos han evolucionado a lo largo de la historia de Occidente, sin embargo, algunos de sus elementos fundamentales han persistido, incluso hasta nuestros días.

El elogio de la alteridad cultural constituye una suerte de racismo cultural invertido (Amselle, 2001), ya que sus discursos parecen ser diametralmente opuestos a aquellos que justifican el racismo o la xenofobia que se suelen denunciar en nuestros días. Cabe entonces preguntarse: ¿cuáles son las lógicas que sustentan este racismo cultural invertido?

\section{Metodología}

Balibar (1990) nos recuerda que toda representación del Otro se apoya en complejas "teorías", las cuales "explican" el fundamento de las divisiones sociales, los orígenes de cada uno de los grupos, o las razones por las cuales unos deben tratar a los otros de ciertas maneras. De hecho, esos discursos son, según Balibar, la causa de comportamientos y de políticas relativas a la alteridad, ya sea para favorecer o para atacar a ciertos Otros. El presente artículo está basado en un análisis hermenéutico de esos discursos o "teorías", comparando sus diferentes contenidos y reflejando sus implicaciones.

En un primer momento, retomaremos textos de algunos autores conocidos en la historia occidental, como De Las Casas, Montaigne, Diderot o Rousseau. En una segunda parte, nos basaremos en el análisis de los discursos emitidos por actores pertenecientes a movimientos o grupos sociales más recientes en la historia, donde también encontramos la idealización del Otro no europeo. En cada uno de estos discursos, se analizaron las estructuras conceptuales que los componen, con el fin de desvelar los sistemas de creencias y de valores (Van Dijk, 2005) subyacentes. Posteriormente, las características principales de cada uno de los discursos fueron estudiadas comparativamente, lo cual permitió encontrar algunos patrones comunes a lo largo del tiempo. Además, se consideró

Todas las citas en castellano que provienen de textos en francés, corresponden a nuestra traducción. 
la situación social desde la cual se producen los discursos, la manera en que esta situación es representada por los participantes (Van Dijk, 2005), así como la posición social de los autores de dichos discursos, todo lo cual permite comprender mejor el sentido de sus términos, al igual que algunas de sus consecuencias.

Este análisis implica reconocer que las prácticas discursivas construyen los objetos mismos de los que hablan (Foucault, 1969). Así, se observó la manera en que ciertos discursos han construido un Otro cultural. Estos discursos, a su vez, se entienden como el producto de sistemas de clasificación social (Descola, 2005), en los cuales se atribuye una serie de cualidades y comportamientos a los sujetos clasificados en una u otra categoría.

\section{Más allá del "buen salvaje": fundamentos e implicaciones culturales}

Una de las imágenes positivas del Otro más conocidas en la historia moderna de Occidente, es la del "buen salvaje". Este concepto se asocia en el mundo anglosajón y en América Latina al filósofo Jean-Jacques Rousseau. Sin embargo, aunque este autor efectivamente revivió y potenció la difusión de este concepto a partir del siglo XVIII, Michel de Montaigne ya lo había planteado en el siglo XVI. Sobre esto volveremos más adelante.

El concepto del buen salvaje se construye en parte sobre las bases del mito de la Antigüedad grecolatina, según el cual habría habido una Edad de Oro donde la humanidad era más feliz y justa (Mouralis, 1989). De hecho, en la Antigüedad romana, existieron narrativas que contrastaban la decadencia de su sociedad presente, con las cualidades de la sociedad romana de tiempos precedentes, caracterizada por la ruralidad y un estilo de vida más simple, entre otras cosas. Paralelamente, las cualidades de la Edad de Oro fueron imaginadas en la alteridad. Por ejemplo, el romano Tácito (Mouralis, 1989, p. 20), en su estudio sobre Germania (el Otro con respecto al Imperio romano), utilizó su texto para denunciar los defectos de su propia sociedad: los excesos de los poderosos, la intolerancia, la crueldad, etc.

Este tipo de esquemas de representación se manifestó de nuevo en la era de los viajes y los descubrimientos europeos a partir del siglo XV. Los europeos de aquellas épocas frecuentemente asociaron los habitantes de las tierras descubiertas con las condiciones supuestamente propias de tiempos pretéritos. "El viaje a un lugar lejano se considera frecuentemente como un viaje al pasado" (Fauvelle-Aymar, Bon y Sadr, 2007, p. 25). Esta perspectiva da lugar a una concepción "tradicionalizante" de los otros pueblos (p. 40). Es decir, el Otro lejano se ha identificado como poseedor de culturas que viven en condiciones "tradicionales", similares a las que el Nosotros habría vivido anteriormente. Este es un principio evolucionista, pero cuando el pasado es asociado a características positivas (siguiendo el modelo del mito de la Edad de Oro), el Otro también recibe algunas de estas características ${ }^{3}$.

La noción del "buen salvaje" está profundamente arraigada en la historia de las ideas en Occidente. "Ever since the West became the West, Robinson has been looking

Es importante tener en cuenta que este es un proceso de "invención de la tradición" (Hobsbawm, 1992). 
for Friday"4 (Trouillot, 2003, p. 17). Por demás, la utilización de la imagen del Otro para proyectar estados ideales se encuentra a lo largo de los siglos. "The savage is an argument for a particular kind of utopia" (Trouillot, 2003, p. 17). En efecto, Tomás Moro encontró en las descripciones de América, la inspiración para su obra "Del mejor de los estados posibles y de la isla Utopía" (Todorov, 1991, p. 309). Recordemos que, desde su etimología griega, la palabra "utopía" denota un lugar que no existe. Asimismo, aquel salvaje idealizado tampoco existe por fuera de la imaginación.

Cabe aclarar en este punto que la palabra francesa "sauvage", de donde viene la expresión "bon sauvage" (o buen salvaje) usada por Montaigne, Rousseau y otros, se podría traducir al castellano también como "silvestre". Se trata de un Otro "silvestre", en el sentido en que vive como en un estado de naturaleza, no de acuerdo a la civilización, quizás cercano a aquel estado de vida simple y rural como en el mito de la Edad de Oro. No se trata pues del salvaje como un ser fiero o desbocado. Americo Vespucci coincidió en describir a los salvajes americanos como seres que vivían "conforme a la naturaleza", ya que el explorador italiano no observó características asociadas a lo que se entendía por "civilización", como vestimentas, propiedad privada, subordinación a un rey, prohibiciones sexuales o religión (Todorov, 1991, p. 308).

La cercanía a la naturaleza era vista por algunos como una característica positiva, en referencia al mito cristiano del jardín del Edén. Cristóbal Colón, de una manera casi arquetípica, utilizó referencias bíblicas para describir las Islas del Caribe como un paraíso en la tierra y para describir las cualidades de los primeros pueblos que encontró. Y es que, desde antes de llegar a lo que ahora llamamos América, Colón cree que va a descubrir, en alguna parte, el mismísimo paraíso terrestre (Todorov, 1991, p. 308). El Jardín del Edén es justamente ese lugar maravilloso, donde el hombre vivía en total armonía con la naturaleza, un lugar puro, un estado pasado que perdimos y al cual desearíamos volver. Un Otro cercano a la naturaleza y donde aún no habría la civilización puede ser fácilmente asociado a aquel estado edénico de un pasado mítico. Recordemos que el hombre pierde su lugar en el paraíso porque come del árbol de conocimiento, fundamento mismo de la civilización y sus ciencias.

Los viajeros que continuaron como Colón descubriendo nuevas tierras estaban en buena parte motivados por el deseo de encontrar un mundo mejor, para ellos mismos, razón por la cual, incluso desde antes de viajar, imaginaban esos lugares de destino de acuerdo con sus propios ideales. Existía en algunos de estos viajeros una cierta inconformidad con respecto al lugar donde vivían. Considerando las dificultades que implicaba cambiar la propia sociedad local, con sus pestes, sus tierras usurpadas, sus injusticias, las tierras Otras se vislumbraban como el cambio de vida esperado. "Para quien quiere cambiar de vida, el viaje es el medio más simple" (Todorov, 1991, p. 312).

Bernardino de Sahagún y Bartolomé de Las Casas fueron dos religiosos españoles que actuaron como voceros importantes en contra del comportamiento de los colonizadores

Según el famoso libro "Robinson Crusoe" de Daniel Defoe, "Friday" es el nombre que el europeo asignó al nativo que le acompañaba. 
europeos y a favor de las culturas indígenas en América. De Sahagún (1500-1590), por ejemplo, lejos de considerar que las lenguas nativas eran "demoníacas", dedicó muchos años de su vida a aprender el náhuatl, lengua hablada en América Central, para así poder comprender y transmitir todo lo que pudiera sobre la cultura india (Mouralis, 1989, p. 36). Para este misionero franciscano, existía una riqueza en la diferencia cultural americana que no merecía ser destruida como estaba pasando en aquel período de colonización.

De Las Casas (1474-1566), sin duda el defensor de los "indios" más importante del período de la Conquista, luchó para defender la tesis según la cual los indios tenían alma como los españoles y, por tanto, no debían ser considerados como "bestias", sino que merecían un trato digno y "humano". Su discurso no es común para la época, y se oponía claramente a los intereses de muchos conquistadores. A continuación, algunos extractos de su texto "La Destrucción de Las Indias" (en Stenou, 1998, p. 148):

Dios creó todas estas personas infinitas, de toda clase, muy simples, sin sutileza o cautela, sin malicia, muy obedientes y muy leales a sus dioses naturales y a los españoles a los que sirven, muy humildes, muy pacientes, muy pacíficos y tranquilos, sin ruidos ni agitaciones, sin querellas [...], sin rencor ni odio, ni ganas de venganza. También son [unas] personas muy delicadas y muy cariñosas [...]. [T]ienen poco y que no piden tener muchos bienes temporales, y por lo tanto no son en lo absoluto soberbios, ambiciosos ni codiciosos. Su comer es tal, que parece que aquellos santos Padres en el desierto no estuvieron más limitados [...]. A estos corderos tan dulces, tan cualificados y dotados por su Hacedor y Creador como ha sido dicho, los españoles entraron [... como lobos, leones y tigres muy crueles, hambrientos desde hace mucho tiempo.

Vemos acá claramente que se señalan en los indios una serie de cualidades que, sin duda, son valoradas por el religioso español, al mismo tiempo que este último presenta una fuerte crítica de la actitud de los europeos ${ }^{5}$.

Michel de Montaigne (1533-1592), en particular en el Libro I de los Ensayos, dedica dos capítulos a los pueblos de América e invita al lector a hacerse preguntas tales como: ¿Es la "civilización" superior a las otras formas de vida humana? ¿La conquista europea tiene un fundamento legítimo? En el capítulo titulado "De Los caníbales", el filósofo francés busca convencer a sus lectores de que el canibalismo de los pueblos de América no es casi nunca como se imagina en Europa. Según Montaigne, estos pueblos americanos no se alimentan de carne humana, sino que lo hacen solo con sus enemigos abatidos en el campo de batalla. Por cierto, Montaigne dice que los europeos ("nosotros") tienen prácticas aún más crueles, ya que por castigo o por venganza, someten a terribles torturas a personas todavía vivas y sensibles al dolor (Montaigne, 1992: 209). Montaigne invita al lector a analizar "nuestros propios comportamientos", donde también se encontrarán numerosos defectos. Igualmente, resaltaba las virtudes supuestas de los nativos americanos, diciendo, por ejemplo, que allí estaban ausentes "las palabras mismas que significan la mentira, la traición, el disimulo, la avaricia, la envidia, la crítica [...]" (Montagine, 1992: 206-7).

Cabe notar que el argumento según el cual los indios tenían alma, permitía además justificar la empresa evangelizadora a la cual se dedicaba De Las Casas (Beck, 2009, p. 104) 
Identificando los "salvajes" a un pasado distante e ideal, afirma Montaigne que ellos "todavía están en ese punto feliz de desear solo lo que sus necesidades naturales ordenan: lo que está más allá, es superfluo para ellos" (Montaigne, 1992: 210). Estos Otros estarían entonces libres de los males provenientes de la ambición y la codicia del hombre europeo. Destacamos en itálicas la palabra "todavía" en la cita de Montaigne, para señalar que, implícitamente, se asume que los indígenas permanecen en un estado ideal en el cual nosotros también pudimos haber estado, pero que perdimos, al igual que ellos también podrían perder con el paso del tiempo. En otras palabras, esta también es una visión evolucionista.

Con argumentos algo similares, Jean de Léry (1534-1613), pastor, escritor y explorador que murió unos cuantos años después de Montaigne, consideraba que, en su origen, el hombre era "natural", pero con el paso del tiempo, la civilización avanzó y su vida se hizo más y más artificial. Considerando que este proceso no era necesariamente positivo, De Léry afirma que "no hay razón para que el arte [de la civilización] se lleve los honores, pasando por encima de nuestra grande y poderosa madre naturaleza" ${ }^{\prime \prime}$, a lo que añade en otro parágrafo que los primeros siglos del hombre fueron "los mejores y más felices" (citado por Todorov, 1991, p. 310-311). De nuevo, el pasado idílico y el contacto con la naturaleza son dos conceptos que se vinculan en este sistema de creencias.

Montaigne habla sobre los nativos americanos, pero en realidad este es un pretexto para hablar de su propia Europa, planteando de ella una crítica tan severa como la que encontramos en De Las Casas. Esto permite pensar que su imagen positiva de los "salvajes" estaría en parte influenciada por un deseo de que la "civilización" en la cual vivía fuese distinta. Montaigne pone en tela de juicio la noción de "barbarie" frecuentemente utilizada por otros autores para describir el estado en el que se encontrarían los nativos de otros continentes. En cierta manera, el filósofo francés denuncia desde ese momento lo que hoy llamaríamos un etnocentrismo: "cada uno llama barbarie a lo que no es de su costumbre" (Montaigne, 1992: 205). En este pensador, vanguardista para su época, se manifiesta igualmente un cuestionamiento de la noción de una jerarquía de culturas, según la cual la civilización europea estaría por encima de los otros pueblos.

Un cierto número de autores posteriores (Montesquieu, Voltaire o La Fontaine), sin duda influenciados por Montaigne, retomaron una de sus ideas literarias: la de un personaje proveniente de tierras lejanas que arriba por primera vez a la sociedad europea y la descubre censurable, cuando no absurda. Jean de La Fontaine (1621-1695), por ejemplo, en su fábula "El campesino del Danubio" (La Fontaine, 1974), imagina un labriego de la Antigüedad que viaja a Roma y observa la dominación de los romanos. El autor invita al lector a preguntarse quién es el más "salvaje": los campesinos colonizados que vivían tranquilos, o los Romanos colonizadores con sus injusticias y su violencia. La Fontaine reproduce así el valor de la vida sencilla de los pueblos "primitivos", retomando asimismo algunas ideas de Tácito.

Vemos acá el ancestro de discursos contemporáneos sobre el cuidado de la madre naturaleza. En los discursos indigenistas latinoamericanos, hoy se habla del cuidado de la "pacha mama", como si esta fuera una idea indígena. 
Basado en las descripciones del explorador Bougainville, donde este habla de la vida en Tahití literalmente como en el jardín del Edén, Diderot (1713 1784), por su parte, imagina los tahitianos como viviendo en una especie de estado idílico. En "Suplemento al Viaje de Bougainville", el filósofo imagina diferencias radicales entre los occidentales y los nativos de las tierras descubiertas, y elogia a los tahitianos como una sociedad donde no existe la diferencia entre "lo tuyo" y "lo mío". Pretendiendo que habla un nativo al colonizador europeo, Diderot escribe: "Déjanos nuestras costumbres que son más sabias y más honestas que las tuyas. [... No nos fastidies con tus necesidades ficticias, ni con tus virtudes utópicas" (extractos citados por Mouralis, 1989: 91). Para Diderot, la colonización se presenta como la irrupción violenta de la "civilización" en una sociedad que antes era feliz. Al hablar de los tahitianos, Diderot está reproduciendo un mito con que los europeos ya poseían aun antes de que hubieran descubierto Tahití. El tahitiano imaginario se convierte entonces en un modelo para el europeo.

Para Rousseau (1712-1778), la evolución de las ciencias en Occidente supone un declive de los valores morales. Él también critica la sociedad refinada en la que vive, y supone que en sus orígenes el Hombre estaba en un estado de "pura naturaleza", sin industria, sin lenguaje, sin necesidad de las demás personas, y sin deseo de hacerles daño (Rousseau, 1979). Se imagina así una forma de vida más simple y apacible, en contacto directo con la naturaleza, sin las complicaciones provenientes de la compleja sociedad civilizada. De otra parte, en su Discurso sobre el origen y los fundamentos de la desigualdad entre los hombres (Rousseau, 2013) deja ver también una visión profundamente evolucionista. Aquellos Otros, habitantes de tierras descubiertas por lo europeos, al estar en un estado supuestamente primitivo, serían como los "jóvenes" de la humanidad, donde aún las desigualdades no serían tan marcadas como en la sociedad europea.

Hay que decir, sin embargo, que la noción del "buen salvaje" de Rousseau ha sido frecuentemente mal comprendida. Rousseau es consciente de que ya no es posible retornar a un estado totalmente primitivo, sin ningún grado de civilización. De hecho, para el autor, solo podremos aspirar a un ideal de sociedad mixto entre la civilización y la naturaleza, un justo medio que permita, por ejemplo, el desarrollo de las ciencias (consideradas por él como un avance positivo), al mismo tiempo que se preserven los valores morales que se habrían ido perdiendo.

\section{Siglo XIX}

El desarrollo de la "civilización" referida en los discursos anteriores continuaba literalmente "a toda máquina" durante el siglo XIX. Sin embargo, como es bien sabido, es precisamente en ese mismo siglo que se desarrolla también el romanticismo, un movimiento cultural central en el proceso moderno de idealización del Otro. Este movimiento es abiertamente crítico de las tendencias dominantes que se viven en el siglo XIX. La urbanización debía contrarrestarse con un retorno a la naturaleza, la racionalización debía compensarse con un retorno a las pasiones, el progreso tecnológico no sería necesariamente mejor que la vida tradicional, y así sucesivamente. Este movimiento es el antecesor de una cierta contracultura que se desarrolló en el siglo XX, como veremos más adelante. 
Paralelamente, en áreas del saber como la lingüística y los estudios literarios, se realizan notables esfuerzos por descifrar y recuperar los mensajes secretos y latentes en diferentes culturas del planeta. Igualmente, se pretendía penetrar la simbología subyacente en otras lenguas y tradiciones literarias, como en los textos sagrados persas, hindúes, chinos, etc., o en mitologías antiguas de América, Grecia o Egipto (Bonardel, 1998). En esta época, por ejemplo, se desarrolla la egiptología y el desciframiento de los jeroglíficos, con figuras como Jean-François Champollion y su estudio de la "piedra Rosetta". En Colombia, un movimiento romántico se interesa también por la mitología de los pueblos amerindios, y se encarga de construir imaginarios sobre un pasado indígena glorioso (Langebaek, 2009, p. 78). ${ }^{7}$

En este siglo existieron, además, corrientes de pensamiento que buscaban una sabiduría unitaria de la humanidad, una "philosophia perennis" que habría existido siempre y se encontraría en aquellos pueblos lejanos, ya sea en la distancia geográfica o en tiempos remotos. Cada una de las diferentes tradiciones se imaginaba como partes de "una Tradición única, fraternal y universal" (Bonardel, 1998, p. 985). Moisés, Zarathustra, Krishna o Jesús fueron considerados como "iniciados" en una sabiduría espiritual válida para toda la humanidad.

En contraposición al conocimiento técnico, en este período romántico se ve también una orientación hacia lo esotérico, lo sobrenatural, la parapsicología, los sueños, las "fuerzas desconocidas", todo lo cual se relaciona, según Kristeva (1989) con "una aspiración a aprehender lo extraño, lo extranjero" (p. 267). La mayor parte de los jóvenes románticos pertenecían a sociedades "secretas" que buscaban conocimientos "ocultos" (Lenoir, 2000). Por ejemplo, Herder pertenecía a la "Orden de los Iluminados de Weishaupt"; Forster, a la "Orden Rosacruz"; Schlegel, por su parte, se interesaba por el neoplatonicismo, la kábala, la alquímia medieval y la espiritualidad de un "Oriente eterno" (Lenoir, 2000, p. 2403). Así, vemos que el interés por lo secreto, lo místico, lo esotérico, se combinaba con un interés por las culturas y tradiciones Otras.

Como en autores del siglo XVIII a los cuales nos hemos referido, algunos románticos del siglo XIX continuaron con la idealización del Otro oriental. Para Lenoir (2000), el movimiento romántico y esotérico del siglo XIX constituyó una plataforma importante desde la cual se plantearon múltiples discursos sobre las culturas orientales. Se planteó, por ejemplo, que la India era la cuna de una "época de Oro, con una humanidad perfecta" y el "origen de la espiritualidad más sublime" (Lenoir, 2000, p. 2404). Encontramos entonces elementos similares a los del mito de la Edad de Oro y de una época impoluta, semejantes a los que ya hemos citado, solo que, en este caso, con el subcontinente indio como escenario.

En la segunda mitad del siglo XIX, una de las organizaciones que más contribuyó a difundir la idealización del Oriente, fue la "Sociedad Teosófica", fundada por Madame

Románticos y nacionalistas del siglo XIX realzaron estas tradiciones también con el objetivo fundamentar una identidad nacional (Cohen, 1996). En el caso colombiano, se buscó, en efecto, la imagen positiva de nativo indígena para reforzar una identidad nacional autónoma y autóctona (Pineda, 1997, p. 113). 
Helena Blavatsky y el Coronel Henry Steel Olcott. Entre sus lemas estaba el de "constituir el núcleo de una fraternidad humana, sin distinción de raza, credo, color [...]; promover el estudio de las literaturas, religiones filosofías y ciencias del Oriente, y mostrar su importancia para la humanidad" (citado por Lenoir, 2000. p. 2404). Para esta Sociedad, habría conocimientos ocultos en las otras culturas y en el pasado que podían proporcionar soluciones a los problemas espirituales de la humanidad (Obadia, 1999). Según Blavatsky, el estudio de tradiciones culturales lejanas como las del Tíbet, Japón, China o la India debía ser profundizado para encontrar en sus fuentes primigenias la esencia espiritual de todas las religiones (Hammer, 2004).

Queriendo dar un paso más hacia el Otro idealizado y espiritualizado, algunos de los miembros de la Sociedad Teosófica fueron de los primeros occidentales en declararse budistas (Obadia, 1999). En este proceso, ellos promovieron la idea de que el budismo se considerase como una "enseñanza", y los lamas, como "maestros". Pero ese Otro oriental, que para ser valorado tiene que estar claramente separado de Occidente, empieza a ser cada vez más difícil de encontrar a medida que avanza la colonización. El budismo tibetano, al considerarse como la versión más pura y auténtica del budismo gracias a su aislamiento geográfico y cultural en las altas montañas del Himalaya, suscita el interés de un buen número de occidentales en búsqueda de espiritualidades alternativas (Sarrazin, 2016a). Así, los románticos construyen su propia versión del budismo "original" (López, 2003), un budismo primigenio, o primitivo, por decirlo de otra forma.

\section{Algunos ejemplos del siglo XX hasta nuestros días}

Es bien sabido que la etnología retomó muchas de las ideas primitivistas heredadas de la Ilustración y del romanticismo. Como ciencia social naciente, la etnología tenía por objeto de estudio principal al Otro no occidental, partiendo no solo del supuesto de que esos Otros eran concebibles como islas separadas del sistema-mundo, sino que, además, supuso, prejuiciosamente, que esos Otros eran sociedades en cierta forma estáticas en el tiempo. Sobre esta crítica de la antropología no nos extenderemos, ya que ha sido ampliamente tratada en otros lugares (ver, entre otros, Fabian, 1983; Grimson, 2011; Trouillot, 2003). Lo importante aquí es notar, como veremos más adelante, que la idea de que los Otros son culturas que se detuvieron en el tiempo, es decir, que se mantienen siempre "tradicionales", persiste hasta nuestros días. Esta idea, además, se ha difundido entre la población y se ha trasladado a contextos institucionales, donde ciertos textos antropológicos son utilizados como supuesta base "científica" para justificar programas preservacionistas cuyo fin, en teoría, es el de recuperar y/o conservar las tradiciones de aquellas culturas, de manera que ellas puedan seguir existiendo8.

En el siglo XX, movimientos como el hipismo y la contracultura, en los años 1960 y 1970, son considerados como una "segunda ola" de interés por las culturas ancestrales

Que estas políticas preservacionistas realmente cumplan su fin y beneficien a los grupos étnicos, es algo muy dudable. Para crítica al respecto, ver Sarrazin 2016c 
de Oriente, luego de la "primera ola" que tuvo su más notoria expresión en el romanticismo del siglo XIX (Lenoir, 2000, p. 2410). La principal diferencia entre ambas "olas", es que en el siglo XX encontramos un fenómeno mucho más ampliamente difundido entre la población. Esta mayor difusión se debe en parte al mayor desarrollo de las tecnologías de comunicación y de transporte. Las ideas de Rousseau, Voltaire o Diderot se difunden de manera más amplia, y a ellos se unen autores que de una u otra manera contribuyen a generar un interés por las culturas no occidentales, tales como Herman Hesse (con su famoso libro "Siddharta"), Emerson, Borges, Tolstoi, al igual que filósofos como Schopenhauer, Nietzsche o Bergson (Lenoir, 2000). Por otro lado, el siglo XX permitió la difusión de obras cuyos autores nacieron en Oriente (aunque en contacto constante y directo con las élites occidentales) como Ghandi o Krishnamurti. También se comienza a ver en Occidente un número cada vez mayor de individuos conocidos como gurús, terapeutas o maestros de origen oriental, fundando escuelas de yoga, de meditación, de artes marciales, acupuntura, etc. Los occidentales llegaron así a tener, por diferentes causas, mucho más acceso a lo oriental (y a lo étnico en general).

Cuando movimientos como el hippismo idealizan la alteridad oriental o amerindia, plantean al mismo tiempo una fuerte crítica en contra de la sociedad capitalista dominante, y aspiran a encontrar una nueva forma de vida, recurriendo a modelos supuestamente encontrados en otras culturas. Estas tendencias se expandieron a escala global, teniendo claras influencias en el pensamiento de ciertos sectores de las sociedades latinoamericanas, donde algunos grupos de individuos fundan comunidades de tipo hippie que pretenden vivir en contacto con la naturaleza, alejarse de la civilización, e inspirarse en las comunidades indígenas para vivir una nueva vida (Sarrazin, 2016b). Las comunidades fundadas bajo estos preceptos se pueden considerar como intentos por construir lo que Droit (1997, p. 215) llama "paraísos anti-modernos".

Más tarde, en los años 1980, se observan tendencias culturales de tipo New Age (Wood, 2007), difundidas a escala global y también muy presentes en América Latina (Sarrazin, 2012; De La Torre, Gutiérrez y Juárez, 2013). Allí se encuentran elementos similares a los de la contracultura, entre ellos, la crítica de la cultura dominante considerada como tecnocéntrica, materialista, carente de espiritualidad, y alejada del bienestar interior. Los antídotos a nuestros males podrían estar en las Otras culturas. El yoga, como espiritualidad "oriental" que podemos aprovechar para alcanzar mayor bienestar personal, es solo uno entre muchos ejemplos. El movimiento New Age, así como es orientalista, también puede considerarse, en cierta medida, indigenista, ya que allí las culturas indígenas son valoradas en tanto que espiritualidades basadas en el contacto con la naturaleza, y de las cuales tendríamos mucho que aprender (Sarrazin, 2012). Consecuentemente, los chamanes indígenas se unen al conjunto de maestros orientales para la transformación interior. Esta valoración discursiva de lo indígena también se lleva a cabo, implícita o explícitamente, a través de referencias en contra de la cultura occidental dominante (Briggs, 1996; Halley y Wilcoxon, 1997; Sarrazin, 2015). De nuevo, las sociedades nativas de América serían una suerte de "paraíso perdido". 
No es casualidad que el orientalismo y el indigenismo parezcan confundirse. De hecho, algunos de los elementos con los cuales se construyen los discursos indigenistas contemporáneos en países latinoamericanos corresponden con aquellos que conforman el orientalismo europeo. Las culturas indígenas son reinterpretadas en parte a través conceptos provenientes de la literatura orientalista, la cual también ha sido consumida por las clases medias y altas de estos países (Sarrazin, 2015, p. 176). Englobadas en la misma categoría de "no occidentales", las culturas orientales e indígenas se consideran más espirituales, con características que hemos "perdido", y poseedoras de "sabidurías" útiles para transformar la cultura moderna.

Otros casos en los que la diferencia cultural lejana ha sido representada en términos positivos, los podemos encontramos en grupos de individuos que, proviniendo de familias cristianas, católicas o ateas, han decidido convertirse al islam en diferentes países del mundo. El interés por el islam en Occidente es llamativo, considerando la amplia circulación de representaciones negativas a propósito de esta religión, a lo cual cabe añadir una gran ignorancia de lo que significar ser musulmán. A pesar de todo lo anterior, numerosos individuos occidentales han decidido convertirse en edad adulta y así "vivir islámicamente", (Sarrazin y Rincón, 2015). En sus procesos de conversión, los sujetos conversos se apoyan en procesos reflexivos y sustentan su decisión mediante sofisticados discursos a favor de esta alteridad religiosa y cultural ${ }^{9}$.

Las conversiones que han tenido lugar entre los estratos medios y altos de las sociedades occidentales, están "relacionadas generalmente con un malestar que el islam solucionaría", malestar que sería una consecuencia de la "falta de trascendencia de nuestra sociedad", según palabras de los sujetos (Allevi, 1999, p. 124). En Colombia, por ejemplo, el islam como expresión de alteridad cultural se contrasta con la decadencia occidental donde se habrían perdido los valores (ya Rousseau lo había dicho). Entre estos nuevos musulmanes se enfatiza la necesidad de recuperar los marcos trascendentes para dar sentido a la vida humana (Sarrazin y Rincón, 2015, p. 141-142). De nuevo, encontramos un rechazo del modelo occidental dominado por el liberalismo y el secularismo ${ }^{10}$. Así como ocurre en los casos que hemos mostrado anteriormente, la construcción de una imagen positiva del islam se basa en el deseo de una vida diferente, la cual es imaginada gracias al acceso a una religión y una cultura provenientes de un lugar lejano y originadas en un pasado remoto.

\section{Discusión y conclusiones}

En su influyente trabajo, Hammer (2004) se pregunta (sin proporcionar una respuesta definitiva) por los factores conducentes a que ciertas doctrinas y prácticas modernas hayan sido adscritas a culturas tan distintas como el Tíbet, Egipto, los Celtas, los poli-

\footnotetext{
9 Siguiendo a Geertz (2001), entendemos la religiosidad como parte indisociable del sistema cultural, por lo que un cambio religioso es también un cambio cultural.

10 La pérdida de fe en las promesas del Progreso moderno es un denominador común que explica el reavivamiento religioso observado en muchos países del planeta (Asad, 2007).
} 
nesios o los indígenas amazónicos (p, 139. Nuestro énfasis). Se trata, primero que todo, de una demanda difusa de formas de vivir diferentes por parte de los europeos y/o sus descendientes. En los discursos modernos que hemos analizado acá, las otras culturas, los otros pueblos lejanos, las gentes de otras latitudes se han convertido en un modelo ideal donde no existiría lo malo del Nosotros, y en cambio sí existiría lo que se considera deseable. Este es un Otro imaginado como radicalmente separado y, aún más, opuesto a la sociedad donde se vive" ${ }^{11}$, un Otro ligado al pasado, próximo de la naturaleza, alejado del materialismo e inclinado a la espiritualidad, entre otras características.

Esta es una forma de primitivismo no reconocida como tal en la actualidad. Aunque hoy en día la palabra "primitivo" no se use y sea mal vista para designar al Otro nativo, persiste la noción de que los verdaderos o auténticos Otros (indígenas, orientales, etc.) son aquellos que han preservado sus tradiciones "ancestrales" o "milenarias". Es gracias a esta preservación, que ellos poseerían todas aquellas características que los convierten en cultura valorada. Esa asociación entre alteridad y primitivismo permite la transferencia de las cualidades de un pasado idealizado, idealización que, a su vez, proviene de los mitos de una Edad de Oro y de un Jardín del Edén.

Se trata, además, de una visión positiva de la alteridad que se fundamenta en una visión negativa de la identidad. Los supuestos habitantes de "paraísos anti-modernos" poseerían la clave para solucionar nuestros problemas y contrarrestar nuestras falencias. Esta tendencia parece haber tomado fuerza en las últimas cinco décadas, y ello se da al mismo tiempo que se duda de que la Modernidad pueda encontrar por ella misma o en ella misma la solución a sus propios problemas (soledad, crisis existenciales, confusión, estrés, desigualdades, contaminación, destrucción del medio ambiente, etc.). El retorno a la naturaleza, así como supuestamente vive el salvaje o vivíamos nosotros antes, es sobre todo una huida de las complicaciones que sufre el individuo en una sociedad compleja como la "civilización".

La idea de que la solución a los problemas de la humanidad se encontrará en una sabiduría proveniente de sociedades "tradicionales" (es decir, del pasado) ha persistido a lo largo de los siglos, aunque a veces se oculte latente, y otras veces incorpore nuevos significantes. De cualquier manera, las características de los discursos sobre las otras culturas o religiones, como señala Said (2004), dependen de las condiciones de las sociedades que los producen. Las representaciones similares que se han dado de polinesios, nativos americanos, tibetanos, etc., se deben a los marcos interpretativos y a los intereses comunes de los occidentales que las construyen y reproducen.

Estas formas de idealización del Otro, aunque muchas veces en sus discursos pretendan favorecer simbólicamente a los más débiles (los Otros colonizados o marginalizados), se basan en una visión profundamente evolucionista de la humanidad y, además, comparten con otras formas de discriminación, el hecho de atribuir ciertas cualidades a un conjunto de personas, únicamente por el hecho de haber sido identificadas dentro de una categoría

"Esta separación radical y dicotómica entre Occidente y los Otros, es uno de los problemas fundamentales de esta ideología. Para una crítica de esta división, expresada en la frase "the West and the Rest, ver Hall (1992). 
específica (como "indígenas, "tibetanos" o "polinesios"). Por eso Todorov (1986, p. 10) afirma que, "así como es abusivo declarar que alguien tiene razón simplemente porque es más fuerte, es inapropiado declarar que los débiles siempre tienen razón". Parafraseándolo, podemos decir que, así como es indebido atribuir características comportamentales negativas a una persona por su color de piel, también es indebido asumir que un conjunto de personas posee las cualidades que nosotros valoramos, solo porque se le clasifica como "no occidental". Los ejemplos que acá hemos presentado son casos de una esencialización de la alteridad, lo cual impide reconocer el continuum de diferencias que caracterizan las realidades sociales, la heterogeneidad que existe tanto entre el "Nosotros", como en el "Otros". La búsqueda del Otro auténtico (es decir, esencializado) termina ocultando la complejidad de la diversidad cultural, conservando así su Otro ficticio y retóricamente útil.

Por otro lado, los discursos de crítica cultural en los cuales se enmarca la idealización del Otro tienen la consecuencia de difundir los valores morales de las personas que reproducen dichos discursos. Esto es particularmente paradójico, si se tiene en cuenta que esas personas generalmente pertenecen a las clases acomodadas de la misma sociedad occidental que critican. Aunque un cierto orientalismo o un cierto indigenismo elogien las virtudes de las culturas orientales o indígenas, estos discursos son una forma de hegemonía cultural en la actualidad. Quienes elogian cierta alteridad, es decir, quienes difunden ese discurso tan políticamente correcto en la actualidad, se posicionan como aquellos que tienen el derecho y la autoridad para juzgar a los demás. Si bien es cierto que este elogio quizá proviene de un sector minoritario y no necesariamente el más poderoso económicamente, recordemos que el concepto de hegemonía, tal como lo planteara Gramsci, permite comprender que siempre pueden existir pugnas entre sectores de la sociedad por asumir un liderazgo moral, intelectual, cultural (Turner, 2003, p. 178). La apología de la diferencia cultural expresa valores que se presentan tácita o abiertamente como superiores.

Por otro lado, la idealización del Otro debe entenderse en el marco de una tendencia cultural más amplia que caracteriza a Occidente (pero que, de ninguna manera debe considerarse como universal o innata): la búsqueda insistente y persistente de un mundo Otro $^{12}$, de un sí mismo mejorado, de una vida distinta y mejor. Esta Otra vida mejor se ha imaginado de diferentes formas según las épocas: la Edad de Oro, el Edén, el paraíso terrenal, la sociedad primitiva, la vida natural, las otras culturas, etc. Primero quizá se imaginó como la posibilidad de que la sociedad o el Hombre en general se transformaran, luego empieza a tomar cada vez más importancia la idea de una transformación individual ("interior", "espiritual"...). En cualquiera de los casos, el Otro se concibe como fuente de inspiración para lograr el cambio esperado.

Esa Otra vida mejor se ha imaginado a través de la noción de Progreso, y, más recientemente, en el ideal de "evolución (o progreso) personal". En cualquier caso, lo mejor puede estar en el pasado o en el futuro. El ideal moderno de Progreso, centrado en el

12 A este propósito, títulos de libros como "El Chamanismo: el otro hombre, la otra selva, el otro mundo. Entrevistas a especialistas sobre magia y la filosofía amerindia" (Jiménez y James, 2004), son la expresión de este elogio de la alteridad. 
crecimiento económico, el desarrollo tecnológico y, en general, la fe en las capacidades de la civilización occidental plantea que lo mejor está en el futuro; en consecuencia, lo primitivo, lo tradicional, debe ser dejado atrás y es representado en términos negativos. De otro lado, los discursos románticos o de las últimas décadas (también muy modernos) plantean que lo mejor pudo estar en el pasado, ya que el futuro que nos espera -"tal como vamos" - es visto con cierta desconfianza, cuando no con pesimismo; en consecuencia, se intenta recuperar las tradiciones, "volver" al contacto con la naturaleza, y se admira el Otro tradicional (antes llamado "primitivo" o "salvaje").

Aunque parezca contradictorio a primera vista, los discursos a favor del progreso, y aquellos en contra del progreso, de la modernidad o de la civilización occidental, provienen del mismo mito occidental que lleva a los unos y a los otros a esa búsqueda constante de otra vida mejor. Ambos creen que es necesario transformar el mundo social e intervenir para cambiar las tendencias del presente. Este transformismo es una característica típicamente moderna y muy contraria al pensamiento de sociedades no modernas. Para difundir las imágenes positivas del Otro se requiere, en efecto, de un esfuerzo considerable de transformación, y se requiere imponer la valoración de lo "tradicional" o de la alteridad cultural, en contra de las corrientes de pensamiento adversas.

Pero, la creencia en que es necesario intervenir y transformar, y el deseo de imponer los valores propios ino son justamente características que han llevado a la civilización moderna a convertirse en una gigantesca máquina de destrucción de las otras culturas y de la naturaleza tal como existían previamente?

\section{Referencias bibliográficas}

Allevi, S. (1999). Les convertis à l'Islam : les nouveaux musulmans d'Europe. Paris: L'Harmattan.

Amselle, J. P. (2001). Branchements. Anthropologie de l'universalité des cultures. Paris: Flammarion.

Asad, T. (2007). Explaining the Global Religious Revival. The Egyptian Case. En G. Haar y Y. Tsuruoka. (Eds.). Religion and Society: An Agenda for the 21 st Century. International Studies in Religion and Society, Vol. 5 (pp. 101-121). Leiden: Brill.

Balibar, E. (1990). Y a-t-il un 'néo-racisme'?. En E. Balibar e I. Wallerstein (Eds.). Race, Nation, Classe. Les Identités Ambiguës (28-39). Paris: La Découverte.

Bartra, R. (1998). El Salvaje en el espejo. México D. F.: Ediciones Era.

Beck, U. (2009). El Dios personal. La individualización de la religión y el "espíritu" del cosmopolitismo. Barcelona: Paidós.

Bernand, C. E Gruzinski S. (1992). De la Idolatría. Una arqueología de las ciencias religiosas. México D. F.: Fondo de Cultura Económica.

Bonardel, F. (1998). Orient, orientalisme. En J. Servier (Ed.). Dictionnaire Critique de l'Esotérisme (pp. 980997). Paris: Presses Universitaires de France.

Briggs C. (1996). The politics of discursive authority in research of the Invention of Tradition. Cultural Anthropology, 11 (4), 435-469. 
Cohen, A. (1996). Folklore. En D. Levinson y M. Ember (Eds.). Encyclopaedia of Cultural Anthropology, Vol. 2 (pp. 501-502). New York: Henry Holt and Company.

Descola, P. (2005). Par-delà nature et culture. Paris: Gallimard.

De La Torre, R., Gutiérrez, C. y Juárez, N. (2013). Variaciones y apropiaciones latinoamericanas del New Age. México D. F.: Ciesas, Colegio de Jalisco.

Droit, R. P. (1997). Le culte du néant. Paris: Seuil.

Fabian, J. (1983). Time and the Other. How anthropology makes its object. New York: Columbia University Press.

Fauvelle-Aymar, F., Bon, F., Sadr, K. (2007). L'Ailleurs et l'avant. Eléments pour une critique du comparatisme ethnographique dans les études des sociétés préhistoriques. L'Homme, 184, 25-46.

Foucault, M. (1969). L'Archéologie du Savoir. Paris: Gallimard.

Geertz, C. (2001). La interpretación de las Culturas. Barcelona: Gedisa.

Grimson, A. (2011). Los límites de la cultura. Crítica de las teorías de la identidad. Buenos Aires: Siglo XXI.

Haley B., Wilcoxon, L. (1997). Anthropology and the Making of Chumash Tradition. Current Anthropology, 38 (5), 761-794.

Hall, S. (1992). The West and the Rest. Discourse and Power. En S. Hall y B. Gieden (Eds.). Formations of Modernity (pp. 275-332). Cambridge: Polity Press.

Hammer, O. (2004). Claiming Knowledge: Strategies of Epistemology from Theosophy to the New Age. Leiden: Brill Academic Publishers.

Hobsbawm, E. (Ed.) (1992).The Invention of Tradition. New York: Cambridge University Press.

Jiménez, A., James, A. (Eds.) (2004). El Chamanismo: el otro hombre, la otra selva, el otro mundo. Entrevistas a especialistas sobre magia y la filosofía amerindia. Bogotá: ICANH.

Joffe, H. (2005). L'Autre et la construction identitaire. En M. Sánchez-Mazas y L. Licata (Eds.). L'Autre. Regards psychosociaux (pp. 95-116). Grenoble: Presse Universitaires de Grenoble.

Kristeva, J. (1989). Étrangers à nous-mêmes. Paris: Fayard.

Langebaek, C. H. (2009). Los herederos del pasado: Indígenas y pensamiento criollo en Colombia y Venezuela. Bogotá: Universidad de Los Andes.

La Fontaine, J. d. (1974). Fábulas. Medellín: Bedout.

Lenoir, F. (2000). Les Spiritualités Orientales en Occident. En F. Lenoir y Y. Tardan-Masquelier (Eds.). Encyclopédie des Religions. Vol. II (pp. 2403-2417). Paris: Bayard.

López, D. (2003). Fascination Tibétaine. Paris: Autrement.

Maldonado-Torres, N. (2008). Sobre la colonialidad del ser: contribuciones al desarrollo de un concepto. En S. Castro-Gómez y R. Grosfoguel (Eds.). El giro decolonial (pp. 127-167). Bogotá: Instituto Pensar -Iesco- Siglo del Hombre Editores.

Montaigne, M. d. (1992). Les Essais. Livre I. Paris: Presses Universitaires de France.

Mouralis, B. (1989). Montaigne et le mythe du bon sauvage. De l'Antiquité à Rousseau. Paris : Pierre Bordas et Fils.

Obadia, L. (1999). Bouddhisme et Occident. La diffusion du Bouddhisme Tibétain en France. Paris: L'Harmattan. 
Pineda, R. (1997). La Constitución de 1991 y la perspectiva del multiculturalismo en Colombia. Alteridades, 7 (14), 107-129.

Rousseau, J.-J. 1979. Las ensoñaciones del paseante solitario. Barcelona: Alianza.

Rousseau, J.-J. (2013). Discurso sobre el origen de la desigualdad entre los hombres. Medellín: Editorial Universidad de Antioquia.

Said, E. 2004. Orientalismo. Barcelona: Random House Mondadori.

Sarrazin, J. P. (2011). Du Marxisme au Chamanisme. Naissance d'un Indigénisme Local à l'Heure Globale. Saarbrücken: Éditions Universitaires Européennes.

Sarrazin, J. P. (2012). New Age en Colombia y la Búsqueda de Espiritualidad Indígena. Revista Colombiana de Antropología, 48 (2), 139-162.

Sarrazin, J. P. (2015). Representaciones sobre lo Indígena y su vínculo con tendencias culturales globalizadas. Anagramas. Rumbos y Sentidos en la Comunicación, 14 (27), 163-184.

Sarrazin, J. P. (2016a). Budismo universal, budismo individual. Análisis del interés por la espiritualidad oriental en Occidente. Revista Escritos, 54 (en prensa).

Sarrazin, J. P. (2016b). Estructura, anti-estructura y sistema-mundo en una comunidad alternativa. El caso de los 'Jipi-koguis' en la Sierra Nevada de Santa Marta. Revista Hallazgos, 13 (25), 157-175. Doi: http://dx.doi.org/10.15332/s1794-3841.2016.0025.07.

Sarrazin, J. P. (2016c). Avatares del pluralismo. Usos y abusos del concepto de diversidad cultural en medios institucionales. Principia Iuris, 13 (26), 55-73.

Stenou, K. (1998). Images de l'Autre. La différence: Du mythe au préjugé. Paris: Seuil.

Todorov, T. (1986). Le croisement des cultures. Communications, 43, 5-26.

Todorov, T. (1991). Nosotros y los Otros: reflexión sobre la diversidad humana. México: Siglo XXI.

Trouillot, M.-R. (2003). Global transformations. Anthropology and the Modern World. New York: Macmillan.

Turner, G. (2003). British Cultural Studies. An Introduction. London: Routledge.

Van Dijk, T. (2005). Ideología y análisis del discurso. Revista Internacional de Filosofía Iberoamericana y Teoría Social, 10 (29), 9-36.

Visonneau, G. (2002). L'Identité Culturelle. Paris: Armand Colin.

Wood, M. (2007). Possession, power, and the New Age: ambiguities of authority in neoliberal societies. Aldershot: Ashgate. 